\title{
Examining the Determinants of Delayed Access to Primary Healthcare in Men
}

\author{
Olubunmi Olanrewaju $^{1} \quad$ Adeola Abosede Adeniyi $^{2}$ \\ 1.Southern University and A \& M College, Department of Public Policy \& Urban Affairs \\ 2.Southern New Hampshire University, International Business
}

\begin{abstract}
Men are more reluctant to seek health care and it is putting them at risk. Delayed access to primary healthcare has a large impact on their health but timely access to health services aims to achieve optimum health outcomes. This paper builds on World Health Statistics 2019 report that men are likely to die earlier than women due to uneven access to health services. Several determinants could drive disparities in access to health care between men and women. This study explores the relevance of variables that can induce delayed access to primary healthcare for men and to what extent these factors are specific to health. Regression analysis carried out suggests that masculinity and health literacy explain differences in health care access. Tailoring useful interventions can facilitate appropriate health care seeking behaviors in men.
\end{abstract}

Keywords: Accessibility, Primary healthcare, Delayed Access, Health service utilization

DOI: $10.7176 / \mathrm{JBAH} / 9-14-04$

Publication date:July $31^{\text {st }} 2019$

\subsection{Introduction}

Historically, women have lived longer than men in almost every country in the world (Austad, 2006). U.S. men are 1.5 times more likely than women to die from heart disease, cancer and respiratory diseases and they die, on average, five years earlier than women (Murray-Law, 2011). According to World Health Organization (2019), men are likely to die earlier than women due to uneven access to health services. The finding that men have lower levels of primary care use compared to women suggests that men disregard early signs of disease and seek medical advice very late (Galdas et al., 2005; Juel \& Christensen, 2007). Women were found to be more interested in health (Green \& Pope 1999), to report more symptoms (Kroenke \& Spitzer, 1998) and to obtain primary healthcare than men did. One possible explanation is that men are more reluctant to go to the doctor (Sanchez \& Himmelstein, 2016).

Financial barriers to care, particularly among low-income people have been greater in the United States than in other high-income countries (Squires \& Anderson, 2015). While the affordability of health care has long been recognized as a central element of access, many patients face barriers that extend beyond their ability to pay for services, such that centers on nonfinancial issues (Kullgren et. al, 2012). Significant socioeconomic reasons for delayed access have received limited attention despite the growing body of studies that highlight a trend of men's reluctance to seek treatment when they become ill and policy makers' inattention to these reasons could potentially lead to adverse consequences. The most commonly proposed explanations are biological risks; risks acquired through social roles, lifestyle and behaviors; and differential healthcare access, treatment and use (Case \& Paxson, 2005). This study examines the factors causing men to postpone going to the doctor until later stages of disease development and to what extent these factors contribute to delayed access.

Primary health care has been proven to be a highly effective and efficient way to address the main causes and risks of poor health and well-being today, as well as handling the emerging challenges that threaten health and well-being tomorrow (WHO, 2019). The Commission on Chronic Illness in the United States described primary care as basically stopping illness before it begins and there are determinants to this type of care. For example, factors related to use of preventive services such as general checkups, immunization and vaccinations differ from those related to diagnosis and treatment (National Center for Health Statistics, 1965a). Access to health care is a multidimensional process that starts with one's ability to identify a health care need, seek and reach health services, obtain and use it, and have the need for the service fulfilled (Andersen, 1995; Levesque et al, 2013). Access to comprehensive, quality health care services is important for promoting and maintaining health, preventing and managing disease, reducing unnecessary disability, preventing premature death, and achieving health equity (Weahkee, 2017). Historically, Americans have experienced variable access to care based on race, ethnicity, socioeconomic status, age, sex, disability status, sexual orientation, gender identity, and residential location (AHRQ, 2017)

In the framework by Levesque et al. (2013), they identified five dimensions of accessibility as approachability, acceptability, availability and accommodation, affordability, and appropriateness. In their study which was based on the experiences and resistances faced by individuals in accessing health services, they argued that these five dimensions can act as barriers to access health care at various stages from initiation of the health care seeking process to the actual benefit from available options for care. Shenghelia et al. (2003) 
attempted to capture seven individual or health systems variables that may influence accessibility as resource availability, physical accessibility, affordability, cultural acceptability, provider quality, adherence, and strategic choice. Perhaps, a more comprehensive view on access should consider the fourth phase of Andersen \& Newman (2005)'s framework of health services utilization on features of individuals (predisposing and enabling factors) and their needs (perceived and evaluated health status). Oksuzyan et al. (2008) suggested that a trend of delayed help-seeking behavior in men is as a result of behavioral differences such as risk-taking or reluctance to seek and comply with medical treatment. In many circumstances, men experience poorer health outcomes than women do, therefore health planning needs to allow for the different needs of men and women, including exposure to risk factors, barriers to access and health outcomes (WHO, 2019).

Access can be seen as a continuum: even if care is available, many factors can affect ease of access to it, for example, the availability of providers who will accept a person's insurance (including Medicaid), ease in making an appointment with a given provider, the ability of a patient to pay for care (even if a patient is insured, due to cost-sharing copayments and deductibles), and the difficulty of arranging transportation to and from healthcare facilities (MACPAC, 2016). Men cannot access care if it does not exist in their geographic area, or if providers will not treat them because of insurance or other issues. The lack of health insurance is associated with lower rates of preventive care, delays in necessary care, forgone care, medical bankruptcy, and increased mortality (Christopher et al., 2015). The Kaiser Commission on Medicaid and the Uninsured noted that people who lack insurance coverage have worse access than people who are insured, and 20 percent of uninsured adults in 2015 went without needed medical care because of cost (KFF, 2018). Recent attention to social determinants of health, such as education, economic stability, community safety, and availability of adequate housing and healthful food, has shown that they correlate with healthier populations (ODPHP, 2017).

Courtenay (2011) reported that 'health education is key' because research shows that men have less knowledge about health, and people with the least health knowledge are more likely to be at risk for illnesses and accidents, or to put themselves at risk. Wingard (1984) argued that since women were traditionally more responsible for family health and knowledgeable about pathological signs, they had a higher propensity to use healthcare services than men. Racial and ethnic disparities in health care are also known to reflect access to care and remain significant predictors of the quality of health care received (IOM, 2002). Minority populations have more difficulty than the majority population in locating a "usual source" of medical care, and black and Hispanic adults report greater difficulty than whites in obtaining medical care at a consistent location (IOM, 2002; AHRQ, 2010). Multiple factors contribute to racial disparities in health-care access and utilization, but unconscious bias on the part of medical professionals might also contribute to cause of delayed access to primary healthcare in men. The 2016 annual National Healthcare Quality and Disparities Report $(Q D R)$ provides an overview of the quality of health care received by the US population and highlights continued disparities in care that are experienced by different racial and socioeconomic groups (AHRQ, 2017).

Evidence for male gender as a determinant of delayed access to health care may be related to the role that socioeconomic status play as driver of health inequalities between men and women. Gender stereotypes and related social norms made it culturally more acceptable for women to be sick, report more health problems and get advice about illness, suggesting that sex differences in health could be partially attributed to gender role expectations and responsibilities. Seidler et al. (2000) highlighted the problematic impact of conformity to traditional masculine norms on the way men experience and seek help. Himmelstein \& Sanchez (2014) predicted that the traditional cultural script about masculinity was related to delays in health care-seeking in men after using nested path modelling to test the relationship between social role beliefs (i.e. masculine contingencies) and barriers to seeking health care.

In as much as these factors may explain some portion of the observed gender differences in health care seeking patterns and potentially perceived unmet needs in men, what is less clear is the extent to which socioeconomic inequalities account for disparities between men and women in accessing primary health care. In view of previous studies, what are the significant factors influencing men's reluctance to access healthcare and to what extent are these factors specific to their health? Consequently, the objectives of this study are first, to test the relevance of certain factors and identify predictors that can cause delay in accessing health service and second, to highlight the need for evaluation of strategies to improve access. Interventions to reduce patient delay could be improved by addressing the health-related behavioral, belief, experiential, and emotional traits associated with delay (Kannan \& Veazie, 2014). It is expected that this study will increase help-pursuit, treatment-uptake and effective self-management among men.

The next section discusses the methodology used in the study, followed by the output and interpretation of results. In the final section, the concluding remarks, areas of additional investment and strategies to overcome the challenges are discussed. 


\subsection{Methodology}

2.1 Study Sample and Design

All questionnaires were administered using either in-person interview, computer-assisted interview or online using social media platforms. Simple random sampling was used to select participants. The study was restricted to respondents ( $>18$ years old) in the city of Baton Rouge, Louisiana for which survey contents modules on delayed access to primary healthcare in men and probable determinants as to why men delay medical attention or seek medical advice late. Participants were asked questions about their age, gender, ethnicity, education, and then social, economic or other factors that may cause men to delay seeking primary healthcare. The responses used in this study were from participants with complete responses. Invalid responses to the study outcome such as "do not know" or "not stated" were excluded. Thus, responses from 210 participants were used in the final analysis sample.

Overall, the study sample consisted of men and women, including physicians who are in the primary or emergency (ER) health care sector. Approximately one-third of the participants were less than 26 years old (participants who may still be on their parents' insurance scheme), and at least two-third were more than 26 years old. A majority (77\%) of the respondents were married, $90 \%$ had a college degree or more, and $83 \%$ identified as black. The mean age of participants was 41 years $(\mathrm{SD}=11.92$, range $19-76)$ and $83 \%$ were male.

\subsection{Measures}

For this study, the outcome of interest was the answer to the question "why do you think men delay or seek medical attention later than women?" The explanatory variable was delayed access to primary healthcare in men. Variables were selected based on Andersen and Newman's framework of health services utilization (Andersen \& Newman, 2005). The model postulates that an individual's access to and use of health services is a function of three characteristics: predisposing factors, enabling factors and need factors. The predisposing variables in the study included age (absolute), ethnicity (Asian, Black, Hispanic, White or others), marital status (Married, Single, Divorced or Widowed) and educational status (High school, Some College, College or Graduate). Enabling factors included High Cost of healthcare, Low or No Insurance, Masculinity, Income level, Doctorgender, Availability of service, Culturally competent care, Health literacy and Scheduling issues.

2.3 Statistical Analysis

Descriptive statistics were conducted to examine baseline characteristics of the sample (Table 2.1).

Descriptive Statistics for Key Variables

\begin{tabular}{|l|l|l|l|l|l|l|}
\hline & N & Minimum & Maximum & Mean & Mode & Std. Deviation \\
\hline DelayedAccess & 209 & 0 & 1 & .83 & 1 & .374 \\
AGE & 209 & 19 & 76 & 41.11 & 38 & 11.920 \\
GNDR & 209 & 0 & 1 & .83 & 1 & .379 \\
MRLST & 209 & 1 & 4 & 1.36 & 1 & .754 \\
EDU & 209 & 1 & 4 & 1.64 & 1 & .715 \\
EHNCTY & 209 & 1 & 4 & 1.25 & 1 & .656 \\
HGHCST & 209 & 0 & 1 & .73 & 1 & .444 \\
LINC & 209 & 0 & 1 & .50 & 0 & .501 \\
LNINSUR & 209 & 0 & 1 & .73 & 1 & .444 \\
MSCLNTY & 209 & 0 & 1 & .93 & 1 & .251 \\
DCTGNDR & 209 & 0 & 1 & .24 & 0 & .428 \\
SERAVLTY & 209 & 0 & 1 & .05 & 0 & .224 \\
CCCARE & 209 & 0 & 1 & .29 & 0 & .453 \\
HLTHLIT & 209 & 0 & 1 & .18 & 0 & .387 \\
SCHDL & 209 & 0 & 1 & .78 & 1 & .419 \\
OTHERS & 209 & 0 & 1 & .08 & 0 & .267 \\
Valid N (listwise) & 209 & & & & & \\
\hline
\end{tabular}

Table 2.1: Summary statistics for respondents

Table 2.1 summarizes the dependent variable (delayed access to health care) and all the independent variables. The response variable (delayed access) was a dichotomous variable coded as Yes $=1$ and No=0. The independent variables were grouped into two: (1) The predisposing variables and (2) Enabling factors. The predisposing variables in the study included except for age, were all categorical in nature, which include ethnicity (Black=1, Asian=2, Hispanic=3, White or others $=4$ ), marital status (Married=1, Single=2, Divorced=3 or Widowed $=4$ ) and education (Graduate $=1$, College $=2$, Some college $=3$ and High school=4). Meanwhile, all the enabling factors including High Cost of healthcare, Low or No Insurance, Masculinity, Income level, Doctorgender, Availability of service, Culturally competent care, Health literacy and Scheduling issues were all binary 
in nature coded as $\mathrm{Yes}=1$ and $\mathrm{No}=0$ (see Table 2.1 for more details).

Table 2.1 also reveals that the average age of the male participants is approximately 41 years while the most frequent age of participants is 38 years. Per the data set, male participants were more in this study. In the categorical nature of the respondents, many were black, and married with a graduate degree. More participants responded in the affirmative that high cost, little or no insurance, masculinity and scheduling issues were causes of delayed access to healthcare in men (i.e. since their respective modal values center around Yes=1) while more respondents differed in their response that low income, doctor-gender, service availability, culturally competent care, high literacy and others were causes of delayed access (i.e. since their respective modal values revolve around $\mathrm{No}=0$ ).

\subsection{Discussion}

The study examined the determinants of delayed access in men as they relate to getting primary healthcare, disregarding early signs of diseases or seeking medical advice/attention. About $83 \%$ of the participants stated that men delay access to primary healthcare, $76 \%$ said that men disregard early signs of diseases and $79 \%$ think that men delay medical advice or attention.

The variables used in this study show that the model was statistically significant at $\mathrm{p}<0.01(\mathrm{p}=0.000)$ as seen in Table 3.1. Analysis suggests that masculinity and health literacy cause men to delay healthcare access (Table 3.2)

\begin{tabular}{|l|l|l|l|l|l|l|}
\hline & B & S.E. & Wald & df & Sig. & Exp(B) \\
\hline Step 0 Constant & 1.604 & .185 & 74.941 & 1 & .000 & 4.971 \\
\hline
\end{tabular}

Table 3.1: Variables in the Equation

Significance for Variables

\begin{tabular}{|c|c|c|c|c|c|c|c|}
\hline & & B & S.E. & Wald & $\mathrm{df}$ & Sig. & $\operatorname{Exp}(B)$ \\
\hline Step $1^{\mathrm{a}}$ & $\begin{array}{l}\text { AGE } \\
\text { GNDR } \\
\text { MRLST } \\
\text { EDU } \\
\text { EHNCTY } \\
\text { HGHCST } \\
\text { LINC } \\
\text { LNINSUR } \\
\text { MSCLNTY } \\
\text { DCTGNDR } \\
\text { SERAVLTY } \\
\text { CCCARE } \\
\text { HLTHLIT } \\
\text { SCHDL } \\
\text { OTHERS } \\
\text { Constant }\end{array}$ & $\begin{array}{l}.033 \\
.988 \\
.481 \\
.365 \\
-.201 \\
.468 \\
.595 \\
.726 \\
1.896 \\
.597 \\
.267 \\
.404 \\
-.947 \\
.230 \\
.403 \\
-4.573\end{array}$ & $\begin{array}{l}.021 \\
.513 \\
.343 \\
.309 \\
.310 \\
.451 \\
.455 \\
.482 \\
.835 \\
.522 \\
.978 \\
.503 \\
.490 \\
.501 \\
.837 \\
1.969\end{array}$ & $\begin{array}{l}2.477 \\
\mathbf{3 . 7 1 5} \\
1.971 \\
1.396 \\
.423 \\
1.077 \\
1.709 \\
2.268 \\
\mathbf{5 . 1 6 3} \\
1.309 \\
.075 \\
.646 \\
\mathbf{3 . 7 3 5} \\
.210 \\
.232 \\
5.394\end{array}$ & $\begin{array}{l}1 \\
\mathbf{1} \\
1 \\
1 \\
1 \\
1 \\
1 \\
1 \\
1 \\
1 \\
1 \\
1 \\
1 \\
1 \\
1 \\
1 \\
1 \\
1 \\
1 \\
1\end{array}$ & $\begin{array}{l}.115 \\
.054 \\
.160 \\
.237 \\
.516 \\
.299 \\
.191 \\
.132 \\
.023 \\
.253 \\
.785 \\
.421 \\
.053 \\
.647 \\
.630 \\
.020\end{array}$ & $\begin{array}{l}1.034 \\
\mathbf{2 . 6 8 7} \\
1.618 \\
1.441 \\
.818 \\
1.597 \\
1.814 \\
2.068 \\
\mathbf{6 . 6 6 3} \\
1.816 \\
1.307 \\
1.498 \\
.388 \\
1.258 \\
1.497 \\
.010\end{array}$ \\
\hline
\end{tabular}

Table 3.2: Variable(s) entered on step 1: AGE, GNDR, MRLST, EDU, EHNCTY, HGHCST, LINC, LNINSUR, MSCLNTY, DCTGNDR, SERAVLTY, CCCARE, HLTHLIT, SCHDL, OTHERS.

Bivariate logistic regression was performed to examine the effect of each independent variable on delayed access to healthcare. Relationship between the explanatory variable (i.e. access to healthcare) and other factors were considered statistically significant at $\mathrm{p}<0.10$. There was strong evidence for the relationship between gender, masculinity and delayed access and a weak evidence between health literacy and delayed access to healthcare in men. Masculinity $(\mathrm{p}<0.05)$ reveals that the traditional cultural script about masculinity was related to delay in health-care seeking in men (Himmelstein \& Sanchez, 2014) while the significance of health literacy $(\mathrm{p}<0.1)$ shows that health literacy affects the interaction of individuals with the health care system, which in turn affects their health status and outcomes to care (Nielsen-Bohlman et. al, 2004).

Traditional or cultural script about men is not to show weakness. The need to be strong and endure virtually all ailments in order to fulfil their duty as men leads them to delay healthcare access. Table 3.2 reveals a positive significant relationship between masculinities and delayed access to health care since the associated p-value of 0.023 is less than 0.05 significance level. This implies that $1 \%$ improvement in masculinities will lead to $1.896 \%$ delay in access to health care among men. Therefore, the researchers have enough evidence based on the Wald 
test value of 5.163 to conclude by theorizing that masculinity is a significant contributing factor to delayed access to healthcare among men. This finding is consistent with the findings of Gough (2006) and Good \&Wood (1995). According to Gough (2006), masculinities reflect the structural relationships, norms, and expectations that shape behaviors and practices, and how men reinforce, challenge, and change practices at different times and places. Gough suggests that even when men have health-oriented issues, they do not act upon it at the expense of masculinity. Good and Wood (1995) termed the impact of masculinity as double jeopardy, as the conformity to traditional masculine norms decrease their willingness to seek help. Men that had sought help described experiences of limited disclosure, minimizing severity of symptoms and the magnitude of need in order to maintain masculine status (Cleary, 2012; Johnson et al., 2012). Men deny and conceal their health conditions to present unchallenged masculine identities (O'Brien and Hunt, 2007; 2014). O'Brien and Hunt revealed that participants from their study believed that men were expected to remain silent about their emotional problems. Moynihan (1998) also reported that men adopt a 'strong, silent approach' and must be 'controlled and silent' about their problems. Men are reluctant to talk openly about their problems, whether health-related or otherwise, which presents a real obstacle to help-seeking (Mathewson, 2009). Conversely, owing to gender norms, help seeking behavior is considered by men as incompatible with masculinity (Spitzer, 2005). Discourses on masculinity should therefore avoid perpetuating stereotypes but rather, investigate forms of masculinity that prove conducive to health-positive behaviors to devise strategies that will appeal to more men (Gough, 2006).

Table 3.2 further reveals a negative significant relationship between health literacy and delayed access to health care since the associated p-value of 0.053 is less than $0.10(10 \%)$ significance level. This implies that $1 \%$ improvement in health literacy will lead to $-0.096 \%$ reduction in delayed access in health care among men. Therefore, the researchers have enough evidence based on the Wald test value of 3.735 to conclude by theorizing that health literacy is a significant contributing factor to delayed access in healthcare among men. In relation to health literature, health literacy is perceived as the skills that enable individuals to understand and communicate health information and concerns. It leads men to delay access to health care. According to the Agency for Health Care Research and Quality Report, health literacy may not be related to years of education or general reading ability since an individual who functions adequately at home or work may have inadequate literacy in a health care utilization. Ratzan and Parker (2000) defines health literacy as the degree to which individuals have the capacity to obtain, process, and understand basic health information and services needed to make appropriate health decisions. Nielsen-Bohlman et al. (2004) found that individuals with limited health literacy reported poorer health status and were less likely to use preventive care. Weiss (1999) proposed that adults with low health literacy are less likely to comply with prescribed treatment, make more medication or treatment errors and lack the skills needed to navigate the healthcare system. Literacy impacts health knowledge, health status and access to health services. Consequently, health literacy is an important determinant in the timing between preventive (primary) and curative treatment. A conceptual framework for health literacy by Nielsen-Bohlman et al. (2004) places health literacy as a mediator between individuals and health contexts since it is significant in health promotion and protection, disease prevention, and early screening and maintenance.

\section{Health Literacy Framework}

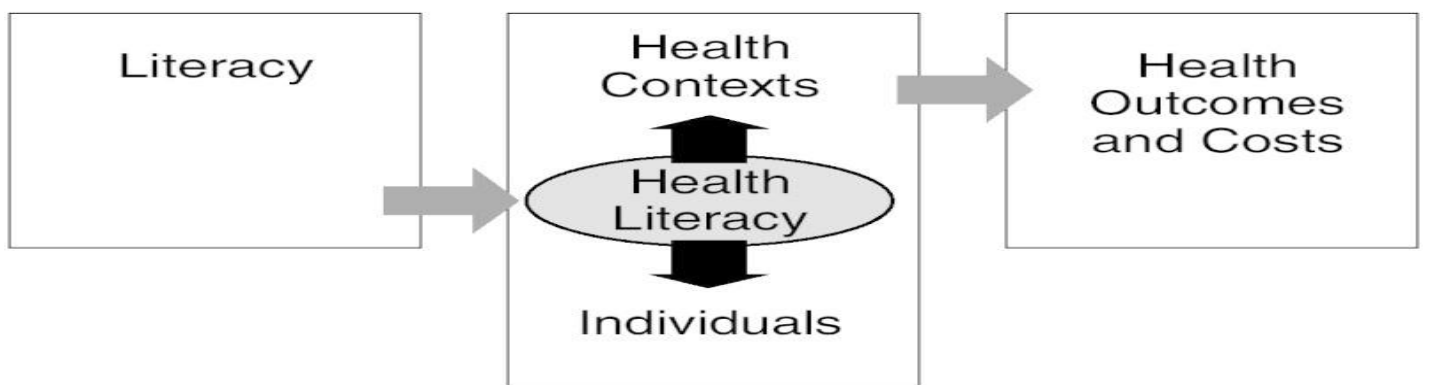

Figure 3.1: Health Literacy Framework. Institute of Medicine (US) Committee on Health Literacy (2004).

\subsection{Conclusion and Recommendation}

Understanding and addressing the gender inequalities in the delivery of health care is critical to ensuring equitable access to high quality health services for both genders (Women and Gender Equity Knowledge Network, 2007). Although different variables were explored in this study, it is our opinion that other variables considered such as high cost of healthcare, insurance, income level, scheduling issues, availability of service and culturally competent care, though determinants of delayed health care access, affect both men and women hence they were not significant in the study. Determinants that potentially delay men's access to primary healthcare observed in this study were masculinity and health literacy.

Tailoring clinical interventions for men may increase the interest and adherence to primary healthcare or 
facilitate appropriate health care seeking behaviors. Men need to be more engaged in prevention, decisionmaking, and self-management as regards their health. Policy makers should increase funding in various healthcare settings to improve health literacy. Improving health literacy can contribute to more informed choice by reducing health risks, increasing prevention and wellness, improving patient safety, patient care and navigation of the health system, reducing inequalities in health care and improving quality of life.

Finally, this study is not an exhaustive investigation of determinants causing delayed healthcare access in men. The two factors (masculinity and health literacy) do not explain most of the gender gap in access to healthcare hence other behavioral factors, biological and social differences that contribute substantially to the explanation of delayed access to primary healthcare among men need to be explored in further studies. As additional research is conducted, new evidence may emerge that will benefit policy makers to make informed decisions to ensure access to care in men. However, further research can investigate how the belief of masculinity and health literacy might be used in campaigns to promote primary healthcare.

\section{References}

AHRQ. (Agency for Healthcare Research and Quality). 2010. 2009 National Healthcare Quality and Disparities Reports. Rockville, MD: AHRQ. https://archive.ahrq.gov/research/findings/nhqrdr/nhqrdr09/qrdr09.html

AHRQ. (2017). 2016 National Healthcare Quality and Disparities Report. Rockville, MD: Agency for Healthcare Research and Quality; July 2017. AHRQ Pub. No. 17-0001. Assessed on July 4, 2019 at https://www.ahrq.gov/sites/default/files/wysiwyg/research/findings/nhqrdr/nhqdr16/2016qdr.pdf.

Andersen, R. M. (1995). Revisiting the behavioral model and access to medical care: Does it matter? Journal of Health and Social Behavior, 36(1), 1-10.

Andersen, R. \& Newman J. F. (2005). Societal and individual determinants of medical care utilization in the United States. The Milbank Quarterly 83(4):10.1111/j.1468-0009.2005.00428.x.

Austad, S.N. (2006). Why women live longer than men: Sex differences in longevity. Gender Medicine, Volume 3, Issue 2, June 2006, Pages 79-92

Case, A., \& Paxson, C. (2005). Sex differences in morbidity and mortality. Demography, 42(2), 189-214.

Christopher, A.S., McCormick D., Woolhandler, S., Himmelstein, D.U., Bor, D.H. \& Wilper, A.P. (2016). Access to Care and Chronic Disease Outcomes Among Medicaid-Insured Persons Versus the Uninsured. American Journal of Public Health 106, 63_69,https://doi.org/10.2105/AJPH.2015.302925

Cleary, A. (2012). Suicidal action, emotional expression, and the performance of masculinities. Social Science \& Medicine, 74(4), 498-505 (doi: 10.1016).

Commission on Chronic Illness in the United States. Prevention of Chronic Illness. Vol. 1. Cambridge, Massachusetts: Harvard University Press; 1957

Courtenay, W. (2011). Six ways to help men get healthy. American Psychological Association. Monitor on Psychology, Vol.42, No. 6 pg. 61

Galdas, P. M., Cheater, F. \& Marshall, P. (2005). Men and health help-seeking behaviour: literature review. $J$ Adv Nurs. 2005; 49:616-23.

Good, G. E. \& Wood, P. K. (1995). Male gender role conflict, depression, and help seeking: Do college men face double jeopardy? Journal of Counseling and Development, 74(October), 70-75

Gough, B. (2006). Try to be healthy, but don't forgo your masculinity: Deconstructing men's health discourse in the media. Social Science \& Medicine, 63(9):2476-88. December 2006

Green, C.A. \& Pope, C.R. (1999). Gender, psychosocial factors and the use of medical services: a longitudinal analysis. Soc Sci Med. 1999;48(10):1363-1372. doi: 10.1016/S0277-9536(98)00440-7.

Himmelstein, M.S. \& Sanchez, D.T. (2014). Masculinity impediments: Internalized masculinity contributes to healthcare avoidance in men and women. Journal of Health Psychology. Volume: 21 issue: 7, page(s): $1283-1292$

IOM (Institute of Medicine). 2002. Unequal treatment: Confronting racial and ethnic disparities in health care. Washington, DC: The National Academies Press (US).

Juel, K. \& Christensen, K. (2007). Are men seeking medical advice too late? Contacts to general practitioners and hospital admissions in Denmark 2005, Journal of Public Health, Volume 30, Issue 1, March 2008, Pages 111-113, https://doi.org/10.1093/pubmed/fdm072

Johnson, J. L., Oliffe, J. L., Kelly, M. T., Galdas, P., Ogrodniczuk, J. S., Johnson, L.

J. \& Ogrodniczuk, S. J. (2012). Men's discourses of help-seeking in the context of depression. Sociology of Health \& Illness, 34(3), 345-361 (doi: 10.1111).

Levesque, J., Harris, M.F. \& Russell, G. (2013). Patient-centered access to health care: conceptualising access at the interface of health systems and populations. International Journal for Equity in Health, 12:18 http://www.equityhealthj.com/content/12/1/18

Kannan, V.D. \& Veazie, P.J. (2014). Predictors of Avoiding Medical Care and Reasons for Avoidance Behavior. American Public Health Association Medical Care.Volume 52 - Issue 4 - p 336-345. 
KFF (Kaiser Family Foundation). (2018). Key facts about the uninsured population. Menlo Park, CA: The Henry J. Kaiser Family Foundation. https://www.kff.org/uninsured/fact-sheet/key-facts-about-theuninsured-population

Kroenke, K., \& Spitzer, R. L. (1998). Gender differences in the reporting of physical and somatoform symptoms. Psychosomatic Medicine. 1998;60(2):150-155.

Kullgren, J. T., McLaughlin, C. G., Mitra, N., \& Armstrong, K. (2012). Nonfinancial barriers and access to care for U.S. adults. Health services research, 47(1 Pt 2), 462-485. doi:10.1111/j.1475-6773.2011. 01308.x

MACPAC (Medicaid and CHIP Payment and Access Commission). (2016). Medicaid access in brief: Adults' experiences in obtaining medical care. Washington, DC: MACPAC. https://www.macpac.gov/wpcontent/uploads/2016/11/Adults-Experiences-in-Obtaining-Medical-Care.pdf (accessed June 27, 2019).

Mathewson, S.H (2009). Man is the remedy of man: Constructions of Masculinity and Health-Related Behaviors Among Yong Men in Dakar, Senegal. Development Studies Institute. Working paper Series LSE ISSN 1470-2320. No 09-91

Moynihan, C. (1998). Theories in health care and research. British Medical Journal, 317, 10721075.

Murray-Law, B. (2011). Why do men die earlier? Monitor on Psychology. June 2011, Vol. 42, No 6

National Center for Health Statistics. (1965). Volume of Physician Visits by Place of Visit and Type of Service, Series 10 , No. 18

Nielsen-Bohlman, L., Panzer, A. M., \& Kindig, D. A. (Eds.). (2004). Health literacy: A prescription to end confusion. Washington, DC: National Academies Press.

O'Brien, R., Hart, G., \& Hunt, K. (2007). "Standing out from the herd": Men renegotiating masculinity in relation to their experience of illness. International Journal of Men's Health, 6(3), 178-200 (doi: 10.3149).

ODPHP. (2017). Healthy People 2020 topics and objectives: Disability and health. Washington, DC: Office of Disease Prevention and Health Promotion. US Department of Health and Human Services. https://www.healthypeople.gov/2020/topics-objectives/topic/disability-and-health

Oksuzyan, A., Juel, K., Vaupel, J. W., \& Christensen, K. (2008). Men: good health and high mortality. Sex differences in health and aging. Aging clinical and experimental research, 20(2), 91-102.

Shengelia, B., Murray, C. J. L., \& Adams, O. B. (2003). Beyond access and utilization: defining and measuring health system coverage. In Health Systems Performance Assessment. Debates, methods and empiricism. Edited by Murray CJL, Evans DB. Geneva: World Health Organization; 221-234.

Sommers, B. D. (2015). Health care reform's unfinished work-remaining barriers to coverage and access. $N$ Engl J Med. 373(25):2395-7.

Spitzer, D.L. (2005). Engendering health disparities. Canadian Journal of Public Health, 96(Suppl 2), S78-96

Squires, D. \& Anderson, C. (2015). US health care from a global perspective: Spending, use of services, prices, and health in 13 countries. Issues in International Health policy brief. The Commonwealth Fund 15:1-15.

Weahkee, M.D. (2017). Wait Time Standards for Primary and Urgent Care Visits in Indian Health Service Direct Care Facilities. Indian Health Service Circular, No. 17-11. https://www.ihs.gov/IHM/circulars/2017/

Weissman, J.S., Stern, R., Fielding, S.L., \& Epstein A.M. (1991). Delayed Access to Health Care: Risk Factors, Reasons, and Consequences. Ann Intern Med. 1991; 114:325-331. doi: 10.7326/0003-4819-114-4-325

WHO. (2019). Primary Health Care. February 2019. https://www.who.int/news room/fact-sheets/detail/primaryhealth-care

WHO. (2019). World health statistics overview 2019: monitoring health for the SDGs, sustainable development goals. Geneva: World Health Organization; 2019 (WHO/DAD/2019.1). Licence: CC BY-NC-SA 3.0 IGO

Wingard, D. L. (1984). The sex differential in morbidity, mortality, and lifestyle. Annu Rev Public Health. 5(1):433-458. doi: 10.1146/annurev.pu.05.050184.002245.

Women and Gender Equity Knowledge Network. (2007). Unequal, unfair, ineffective and inefficient. Gender inequity in health: Why it exists and how we can change it (Commission on Social Determinants of Health, Trans.). Geneva: World Health Organization. 